\title{
A comparison of public and private obstructive sleep apnea clinics
}

\section{A.I. Zonato, L.R. Bittencourt, F.L. Martinho, P. Baiard, S.M. Togeiro, A.A. Benedito-Silva and S. Tufik}

Disciplina de Medicina do Sono, Departamento de Psicobiologia, Instituto do Sono, Universidade Federal de São Paulo, São Paulo, SP, Brasil

\section{Correspondence}

A.I. Zonato

Instituto do Sono

Rua Napoleão de Barros, 925

04024-002 São Paulo, SP

Brasil

Fax: + 55-11-5539-7905

E-mail: aizonato@ terra.com.br

This paper was presented at the 16th Congress of the European Sleep Research Society, Reykjavík, Iceland, June 3-7, 2002.

Research supported by AFIPUNIFESP.

Publication supported by FAPESP.

Received January 27, 2003 Accepted November 4, 2003

\section{Abstract}

The aim of the present study was to compare the clinical findings and polysomnography results obtained at public and private clinics in Brazil, the follow-up after diagnosis, and the therapeutic aspects related to continuous positive airway pressure. Patients who snore and who have obstructive sleep apnea were retrospectively divided into two groups, i.e., public clinic $(\mathrm{N}=307)$ and private clinic $(\mathrm{N}=317)$. Data concerning age, sex, body mass index (BMI), neck circumference, medical history, sleepiness scale, follow-up after diagnosis, and acceptance of continuous positive airway pressure therapy were collected. Mean age was $50 \pm 12$ (range: 15-80) for public patients and $48 \pm 12$ years (range: 19-91) for private patients. Mean BMI was $30 \pm 6$ (range: 19-67) for public patients and $31 \pm 6 \mathrm{~kg} / \mathrm{m}^{2}$ (range: $21-59$ ) for private patients. The public clinic had a significantly higher frequency of women than the private clinic (M:F ratio of 2.0:1 and 6.9:1, respectively). The condition of private patients (apnea-hypopnea index $=31 \pm 25$ ) was more severe than that of public patients (apnea-hypopnea index = $25 \pm 24$ events/h; $\mathrm{P}=0.0004)$. In the public and private clinics, 19 and $15 \%$ of patients were snorers, respectively, and 81 and $85 \%$ of them had sleep apnea. After diagnosis, follow-up was longer in the private group. The continuous positive airway pressure acceptance was similar for both groups ( 32 vs $35 \%$ ), but patients from the public clinic abandoned treatment more than private ones $(65 \mathrm{vs}$ $13 \%)$. Social status was significant in terms of the severity of obstructive sleep apnea age and gender distribution. Private patients look for a diagnosis earlier in the course of the disease than public patients, adhere more to follow-up, and abandon continuous positive airway pressure treatment less than public patients do.
Key words - O bstructive sleep apnea - Social class aspects - Anthropometric aspects

- Continuous positive airway pressure

\section{Introduction}

Obstructive sleep apnea (OSA) is considered to be a medical and public health problem in terms of its consequences for the cardiovascular system (high blood pressure and ischemic heart disease) and excessive daytime sleepiness (causing automobile accidents), affecting mainly obese middle-aged individuals (1-4). Since OSA was first described by Guilleminault et al. (5), some therapeutic modalities have been adopted such as tracheostomy, weight loss, upper airway surgeries, oral appliances, and con- 
tinuous positive airway pressure (CPAP) (6). The use of CPAP is one of the most common treatments for patients with OSA since its efficacy for the improvement of quality of life has been well demonstrated $(7,8)$. The clinical and polysomnography (PSG) features of OSA patients are well-known in the literature, as also are the indication of and compliance with nasal CPAP (9-11). Some individual aspects such as obesity, gender, age, ethnicity, smoking, and alcohol use are closely related to OSA (12-18). Demographic data, clinical findings, PSG features, and CPAP acceptance have not been previously compared between public and private clinics. Patients from these clinics mainly differ in economic status, a fact that can be highly relevant in terms of the principal treatment of sleep apnea considering the high cost of nasal CPAP.

We hypothesize that patients from public and private clinics differ not only in severity of apnea-hypopnea index (AHI) but also in social aspects that might influence treatment with nasal CPAP. The objectives of the present study were: 1) to compare clinical findings and PSG results between public and private clinics, and 2) to compare the followup after diagnosis of OSA and the therapeutic aspects related to nasal CPAP between these groups of patients in Brazil.

\section{Material and Methods}

\section{Study subjects}

All data were retrospectively collected from patient charts at the Sleep Clinic of Universidade Federal de São Paulo, that attends patients referred from the public university hospital and from a private clinic. A total of 624 adult snorers or OSA patients seen from 1997 to 2000 were divided into two groups, namely public clinic $(\mathrm{N}=307)$ and private clinic $(\mathrm{N}=317)$. The inclusion criterion was adult patients with OSA (including snorers without apnea) evaluated by PSG.

\section{Clinical evaluation}

Our Sleep Laboratory is a national reference center staffed by a multidisciplinary group, and the physicians responsible for the respiratory sleep disorders use the same standardized questionnaire to evaluate both public and private patients. The data collected from the charts were age, sex, body mass index (BMI), neck circumference, past and present medical history, Epworth Sleepiness Scale (ESS), follow-up after diagnosis, and acceptance of CPAP therapy. Medical history included presence of hypertension, cardiovascular diseases (myocardial infarction, coronary heart disease, arrhythmia, heart failure, and cerebrovascular accident), asthma, diabetes mellitus, hypothyroidism, nasal obstruction, and nasal allergic symptoms (sneezing, nasal itching, rhinorrhea).

\section{Polysomnography monitoring}

PSG was performed for one full night using a 13-channel SAC Oxford ${ }^{\circledR}$ system (version 10, Oxford Instruments, Inc., Tampa, FL, USA) for the determination of electrocardiogram, oculogram, submental and anterior tibialis electromyogram, nasal and oral airflow (measured with a thermistor), thoracic and abdominal movements, body position, and oxygen saturation measured by pulse oximetry. The sleep stages were scored according to the Rechstaffen and Kales Manual (19), arousal according to ASDA recommendations (20), and respiratory events according to AASM (21) recommendations.

\section{Statistical analysis}

Statistically significant differences between public and private patients were determined by the Mann-Whitney U-test or the chi-square test for two independent samples, depending on the type of the variable. For all tests, the level of significance was set at $\mathrm{P} \leq$ 0.05. Data were analyzed using Statistics for 
Windows software, release 5.1 (Statsoft Inc., 1997).

\section{Results}

The data comparing public to private patients revealed a mean age of $50 \pm 12$ and $48 \pm 12$ years $(P=0.014)$, BMI of $30 \pm 6$ and $31 \pm 6 \mathrm{~kg} / \mathrm{m}^{2}$, neck circumference of $41 \pm 5$ and $43 \pm 4 \mathrm{~cm}$, respectively, with a predominance of men in both groups, and with the private clinic having a higher percent of men than the public (87 and $67 \%$, respectively, $\mathrm{P}$ $<0.0001$ ) (Table 1). The public clinic had a significantly higher frequency of women than the private clinic, with male:female ratios of 2.0:1 for public clinic and 6.9:1 for private clinic. When the groups were divided according to age decade, the majority of patients in both clinics were found to be concentrated between the 4th and 5th decade (Figure 1). The groups differed significantly in the distribution of age decade, with more private than public patients in the 3rd decade and more public than private patients in the 6th decade. Considering the degrees of obesity, the public and private clinics were closely similar, and most patients were concentrated in the mild and moderate categories of obesity in both groups. Among all patients (snorers and OSA patients), the basal PSG study showed a mean AHI of $25 \pm 24$ and $31 \pm 25$ events/h for the public and private clinics $(\mathrm{P}=0.0004)$, respectively, and a lowest oxygen saturation of $78 \pm 12$ and $74 \pm 13 \%(\mathrm{P}=0.0003)$. According to the sleep questionnaire, private patients were similar, with a mean ESS score of $12 \pm 8$ and $13 \pm 6$.

In the past medical history of the public and private groups, hypertension was the major health problem without a significant difference between groups, affecting $36 \%$ of public patients and $34 \%$ of private patients. Hypothyroidism, diabetes mellitus, asthma, and cardiovascular diseases were present at low frequency in both groups, and diabetes mellitus was more frequent among public clinic patients. The anthropometric and PSG data, ESS and medical history of both groups are summarized in Table 1.

On the basis of AHI score, the patients were classified as snorers without apnea (AHI $<5)$, with mild sleep apnea (AHI $=5-15)$, moderate sleep apnea $(\mathrm{AHI}=15-30)$ or severe disease (AHI >30) (21). According to this classification, the groups were significantly different in terms of the severe apnea category, with the private clinic having more

Table 1. Anthropometric and polysomnography data, Epworth Sleepiness Scale, and past medical history of private and public clinic patients.

\begin{tabular}{lcc}
\hline & Public clinic $(\mathrm{N}=307)$ & Private clinic $(\mathrm{N}=317)$ \\
\hline Age (years) & $50 \pm 12$ & $48 \pm 12^{*}$ \\
BMI $\left(\mathrm{kg} / \mathrm{m}^{2}\right)$ & $30 \pm 6$ & $31 \pm 6$ \\
Neck circumference $(\mathrm{cm})$ & $41 \pm 5$ & $43 \pm 4$ \\
Gender $(\%$ males:\% females) & $67: 33$ & $87: 13^{*}$ \\
ESS & $12 \pm 8$ & $13 \pm 6$ \\
Basal AHI (events/h) & $25 \pm 24$ & $31 \pm 25^{*}$ \\
Lowest $\mathrm{O}_{2}$ saturation $(\%)$ & $78 \pm 12$ & $74 \pm 13^{*}$ \\
Hypertension & $36 \%$ & $34 \%$ \\
Hypothyroidism & $3 \%$ & $2 \%$ \\
Diabetes mellitus & $9 \%$ & $3 \% *$ \\
Asthma & $5 \%$ & $6 \%$ \\
Cardiovascular diseases & $6 \%$ & $7 \%$ \\
\hline
\end{tabular}

$\mathrm{AHI}=$ apnea-hypopnea index; $\mathrm{BMI}=$ body mass index; ESS $=$ Epworth Sleepiness Scale; $\mathrm{N}=$ number of patients.

$* \mathrm{P}<0.05$ compared to public clinic patients (Mann-Whitney U-test and chi-square test).

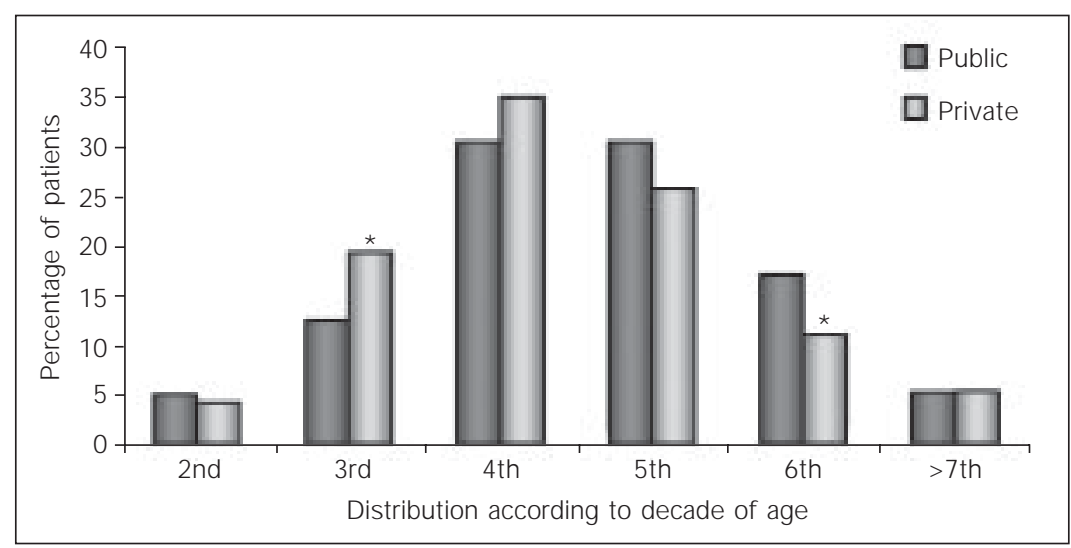

Figure 1. Patient distribution between public and private clinics according to age (2nd: up to 29 years; 3rd: between 30 and 39 years; 4th: between 40 and 49 years; 5th: between 50 and 59 years; 6th: between 60 and 69 years; $>7$ th: 70 years and over). $* \mathrm{P}=0.019$ for 3rd decade and $\mathrm{P}=0.033$ for 6 th decade of age (chi-square test). 
severe patients than the public clinic $(\mathrm{P}=$ 0.002 ; Figure 2). In the public and private clinics, 19 and $15 \%$ of patients, respectively, were considered to be snorers ( $\mathrm{AHI}<5$ ), and 81 and $85 \%$ of them had some degree of sleep apnea (AHI >5), representing the great majority in both groups, without a significant difference between them.

According to the charts, part of the patients in each group had been questioned about nasal symptoms (obstruction or allergy), i.e., $67.1 \%$ of public patients $(\mathrm{N}=$ 209/307) and $74.4 \%$ of private patients $(\mathrm{N}=$ 236/317). Considering just patients who were questioned about nasal symptoms, $75.6 \%$ of those in the public group $(\mathrm{N}=158 / 209)$ and

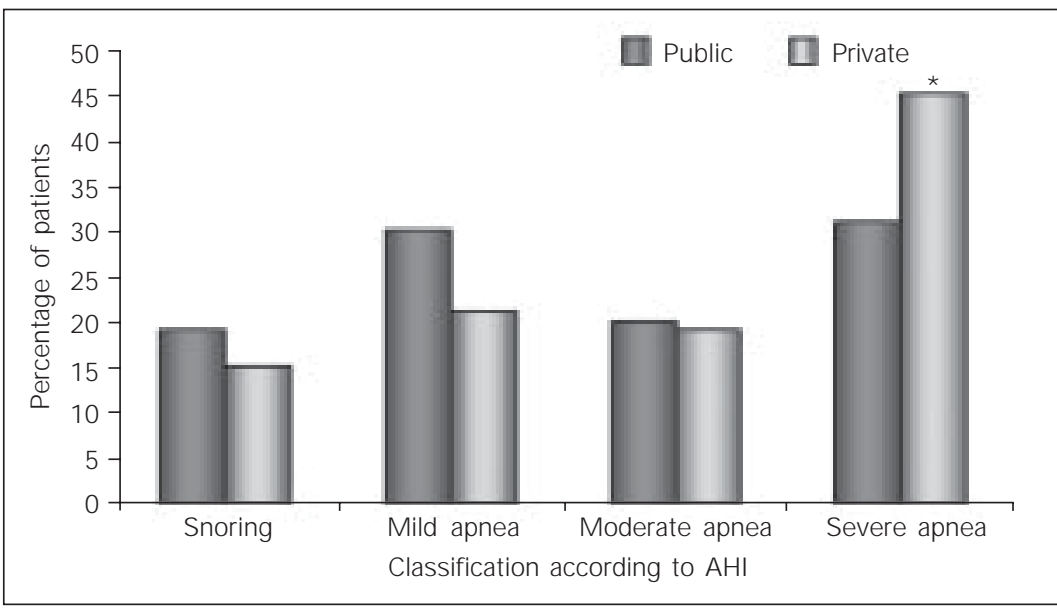

Figure 2. Patient distribution according to $\mathrm{AHI}$ classification between public and private clinics (without apnea: $\mathrm{AHI}<5$; mild: $\mathrm{AHI}=5-15$; moderate: $\mathrm{AHI}=15-30$; severe: $\mathrm{AHI}>30$ events/h). AHI $=$ apnea-hypopnea index. $* \mathrm{P}=0.002$ compared to severe apnea public clinic patients (chi-square test).

Table 2. Comparison of follow-up after diagnosis and of CPAP impact between the public and private clinic patients.

\begin{tabular}{lllc}
\hline & $\begin{array}{c}\text { Public clinic } \\
(\mathrm{N}=307)\end{array}$ & $\begin{array}{c}\text { Private clinic } \\
(\mathrm{N}=317)\end{array}$ & $\begin{array}{c}\text { Odds ratio } \\
95 \% \mathrm{Cl} \text { (range) }\end{array}$ \\
\hline Return after OSA diagnosis & $68 \%(209 / 307)$ & $79 \%(251 / 307)^{*}$ & $0.56(0.38-0.81)$ \\
PSG with CPAP & $35 \%(107 / 307)$ & $43 \%(136 / 317)^{*}$ & $0.71(0.50-0.99)$ \\
Started CPAP treatment & $32 \%(34 / 107)$ & $35 \%(47 / 136)$ & $0.88(0.40-1.56)$ \\
Stopped CPAP treatment & $65 \%(22 / 34)$ & $13 \%(6 / 47)^{*}$ & $12.52(3.68-44.92)$ \\
\hline
\end{tabular}

$\mathrm{Cl}=$ confidence interval; $\mathrm{CPAP}=$ continuous positive airway pressure; OSA = obstructive sleep apnea; PSG = polysomnography.

$* P<0.05$ compared to public clinic patients (chi-square test).
$58.1 \%$ of those in the private group $(\mathrm{N}=137 /$ 236; $\mathrm{P}=0.001$ ) reported a past history of nasal symptoms. Nasal obstruction was the most common symptom, followed by sneezing and nasal itching.

After diagnosis by PSG, the return for a new schedule was higher in the private group, 79 vs $68 \%(\mathrm{P}=0.002)$ (Table 2). A new PSG to evaluate CPAP titration and its therapeutic results was performed in 35\% (107/307) of public patients and in $43 \%(\mathrm{~N}=136 / 317)$ of private patients $(\mathrm{P}=0.039)$. Among patients who performed CPAP titration, $32 \%$ in the public clinic and $35 \%$ in the private clinic started to use CPAP. The status of CPAP acceptance (i.e., patients who started to use nasal CPAP) was closely similar in both groups, but a large part of patients from the public clinic abandoned treatment (65 vs 13, $\mathrm{P}<0.0001)$.

Among the patients using nasal CPAP, the public and private clinics differed in the severity of sleep apnea, with private patients being more severe than public ones, with AHI of $51 \pm 23$ and $42 \pm 28$ events/h $(\mathrm{P}=$ 0.009; Table 3). Patients using nasal CPAP did not differ in terms of symptoms of nasal obstruction or ESS score. Considering only the patients that stopped using CPAP, the difference between the two groups was about apnea severity but this difference was not statistically significant.

\section{Discussion}

The study outcome demonstrated that patients in the 4th and 5th decades of life predominated in both groups, but patients from the private clinic were slightly younger than those from the public clinic. According to the literature, OSA mainly occurs in middle-aged adults and tends to become worse and more prevalent with age $(22,23)$. After the peak between the 4th and 5th decades of age, the distribution showed a decline in the frequency of patients over 60 years of age (Figure 1), a fact that may 
represent a low life expectancy for both groups. Lindberg et al. (12) observed this situation in a study of 2,668 men aged 30-69 years followed up for 10 years. The prevalence of apnea in this series increased up to 50-60 years and was followed by a decrease thereafter. This situation reflects the need to diagnose patients with OSA at the youngest possible age for early treatment, with a possible consequent change in the impact of mortality. The influence of OSA on mortality was reported by some investigators and is related to the severity of apnea as well as to patient age (24-26). The probability of survival is higher in less severe patients and age seems to influence mortality only in patients below the age of 50 according to the study by He et al. (24) and, just below the age of 60 according to the study by Lindberg et al. (26).

The typical patient with OSA is described as an overweight adult male and some studies have shown the important influence of obesity $(13,15)$. In our study, close to $88 \%$ of all patients in the public and private clinics were overweight. Most patients had a BMI between 26 and $40 \mathrm{~kg} / \mathrm{m}^{2}$ and only a few of them had morbid obesity. The weight distribution was not influenced by social class in the patients studied.

As expected, a high predominance of males was noted in both groups, but the public clinic had a higher frequency of women than the private one, with respective M:F ratios of 2.0:1 for public clinic and 6.9:1 for private clinic. One hypothesis for the gender disparity observed between public and private patients in our study is that women from the private clinic may be under-diagnosed, perhaps because they do not feel so comfortable to admit that they snore and so do not seek medical care. When the patients from the two clinics were classified according to gender and age, an interesting distribution was observed (Figure 3). Considering the percentage of patients for each decade of age, there was a different distribution be- tween men and women in the 3rd and 5th decades of life for public patients. Figure 3 shows an increase in the percentage of women from the 4th to the 5th decade of life, which might correspond to the menopausal period, when women present a higher incidence of sleep apnea. However, we did not observe the same occurrence in the distribution of private patients, with a difference being observed only in the 4th decade of life without an increase in the percentage of women com-
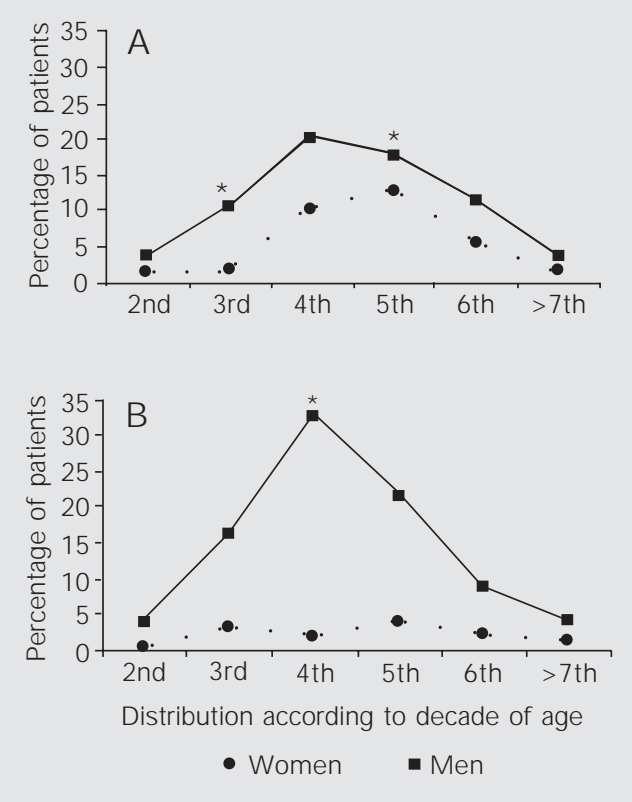

Table 3. Comparison of patients from public and private clinics who started to use CPAP.

\begin{tabular}{lcc}
\hline & $\begin{array}{c}\text { Public clinic } \\
(\mathrm{N}=34)\end{array}$ & $\begin{array}{c}\text { Private clinic } \\
(\mathrm{N}=47)\end{array}$ \\
\hline AHI & $42 \pm 28$ & $51 \pm 23^{*}$ \\
$\quad$ Mild apnea & $6 \%(2)$ & $2 \%(1)$ \\
Moderate apnea & $41 \%(14)$ & $11 \%(5)^{*}$ \\
$\quad$ Severe apnea & $53 \%(18)$ & $87 \%(41)^{*}$ \\
ESS & $13 \pm 6$ & $14 \pm 6$ \\
AHI of patients who & $40 \pm 28$ & $56 \pm 22$ \\
stopped using CPAP & & \\
\hline
\end{tabular}

$\mathrm{AHI}=$ apnea-hypopnea index; CPAP = continuous positive airway pressure; ESS = Epworth Sleepiness Scale; $\mathrm{N}=$ number of patients.

*P $<0.05$ compared to public clinic patients (MannWhitney U-test and chi-square test).
Figure 3. Patient distribution according to age and gender classification for public (A) and private clinics (B) (2nd: up to 29 years; 3rd: between 30 and 39 years; 4th: between 40 and 49 years; 5th: between 50 and 59 years; 6 th: between 60 and 69 years; >7th: 70 years and over). $* \mathrm{P}<0.05$ compared to women (chi-square test). 
pared to the 3rd decade of life.

One question that has not been fully answered is why men are more prevalent than women. Could this be related to the pathology of OSA, to which men are more susceptible? Or could it be that women are not well diagnosed and we are missing them? Young et al. (27) have shown that current clinical indications to evaluate OSA are as appropriate for women as they are for men. Considering men and women with the same level of AHI, they did not find different reported symptoms between them, and snoring was the most sensitive and strongest predictor of sleep apnea for both sexes. The difference in prevalence between men and women seems to decrease during the postmenopausal period when weight gain and central obesity are observed, also associated with aging (28).

In the public and private clinics studied here, 15 to $19 \%$ of subjects had snoring without apnea (AHI <5) and 81 to $85 \%$ of them, i.e., the great majority in both groups, had some degree of sleep apnea (AIH >5). Considering the severity of OSA, private clinic patients had a more severe condition according to $\mathrm{AIH}$ and also to lowest $\mathrm{O}_{2}$ saturation. However, this cannot be explained by BMI because the groups had a closely similar BMI distribution, or by age since the most severe group comprised slightly younger patients. It was observed that the gender ratio was different between these two groups. Considering male and female AHI for both private (male $\mathrm{AHI}=32 \pm 25$ and female $\mathrm{AHI}$ $=21 \pm 21 ; \mathrm{P}=0.001$ ) and public (male AHI $=28 \pm 26$ and female $\mathrm{AHI}=19 \pm 21 ; \mathrm{P}=$ $0.0001)$ patients, it is possible to observe that women had a less severe condition in both groups. The fact that among public patients there was a higher proportion of women than among private patients, and women had a less severe condition can explain, at least in part, why public patients had a less severe condition according to AHI. When past medical history was checked, the only difference was a higher frequency of diabetes mellitus among public patients, possibly related to the fact that public patients were older and so had a higher probability to develop diabetes mellitus. The only difference that could influence the severity was that private patients included more males than public ones.

A past history of nasal symptoms was more frequent at both clinics, but was even more frequent in the public group (75.6 vs $58.1 \%$ ), with more than half of all patients usually reporting some nasal problem. These data should be considered with caution since the numbers were collected retrospectively from the charts, where it was more likely that the physicians would record positive symptoms more than negative ones. According to the literature, 21.9 to $66 \%$ of patients using nasal CPAP usually report some nasal symptoms (29-32). In our study, nasal obstruction was the major problem for both clinics but was more frequent among private patients.

With respect to the return after the OSA diagnosis, private patients complied with follow-up more than public patients. The private clinic had more severe patients according to the AHI and the lowest $\mathrm{O}_{2}$ saturation, a fact that could explain why their patients came back for follow-up and performed PSG with CPAP more than public patients. In Brazil, all the investigation with PSG is supported by the Health Care Agencies or by Public Hospitals, but these organs do not provide CPAP devices for the patients. Public and private clinics did not differ in the acceptance of CPAP treatment (patients who started to use nasal CPAP). In our Sleep Laboratory, public and private clinics receive the same CPAP educational program provided by the same staff. However, the group of public patients using nasal CPAP had a less severe condition considering the AHI and more than half of them stopped using nasal CPAP (Tables 2 and 3). The daytime sleepiness symptom, according to ESS score, was similar for patients using 
nasal CPAP. Among the patients who stopped using CPAP, public patients tended to show a milder degree of apnea than private patients although the difference was nonsignificant. The fact that their illness was milder may explain, at least in part, why public patients abandoned CPAP more frequently than private patients.

Social status did not influence BMI, neck circumference or ESS, but was of clinical significance in terms of OSA severity (patients from the private clinic had a more severe condition) and of gender distribution (the public clinic had three times more women than the private clinic). Also, private patients were younger than public patients. Nearly $60 \%$ of both private and public clinics reported a past history of nasal symptoms. Obesity was highly prevalent in both clinics, but a minority of patients had morbid obesity.

Considering the investigation and treatment of OSA, private patients sought a diagnosis earlier than public ones, came back for follow-up more than public patients did, and abandoned CPAP treatment much less than public ones. Our data indicate that public health programs are needed to improve the use of nasal CPAP by less privileged social class patients and to reduce the occurrence of ineffective treatment.

\section{References}

1. Nieto FJ, Young TB, Lind BK, Shahar E, Samet J M, Redline S, D'Agostino RB, Newman AB, Lebowitz MD \& Pickering TG (2000). Association of sleep disordered breathing, sleep apnea, and hypertension in a large community based study. J ournal of the American Medical Association, 283: 1829-1836.

2. Peppard PE, Young T, Palta M \& Skatrud J (2000). Prospective study of the association between sleep disordered breathing and hypertension. New England J oumal of Medicine, 342: 1378-1384.

3. Peker Y, Hedner J, Kraiczi H \& Loth S (2000). Respiratory disturbance index. An independent predictor of mortality in coronary artery disease. American J oumal of Respiratory and Critical Care Medicine, 162: 81-86.

4. Lavie P (1983). Incidence of sleep apnea in a presumably healthy working population: a significant relationship with excessive daytime sleepiness. Sleep, 6: 312-318.

5. Guilleminault C, Tilkian A \& Dement WC (1976). The sleep apnea syndromes. Annual Review of Medicine, 27: 465-484.

6. Kryeger MH (1992). Management of obstructive sleep apnea. Clinics in Chest Medicine, 13: 481-492.

7. Wright J , J ohns R, Watt I, Melville A \& Sheldom T (1997). Health effects of obstructive sleep apnea and the effectiveness of continuous positive airway pressure: a systematic review of the research evidence. British Medical J oumal, 314: 851-860.

8. Beninati $W \&$ Sanders MH (2001). Optimal continuous positive airway pressure for the treatment of obstructive sleep apneahypopnea. Sleep Medicine Reviews, 5: 7-23.

9. Krieger J , Kurtz D, Petiau C, Sforza E \& Trautmann D (1996). Longterm compliance with CPAP therapy in obstructive sleep apnea patients and in snorers. Sleep, 19: S136-S143.

10. Meurice J C, Dore P, Paquereau J , Neau J P, Ingrand P, Chavagnat J J \& Patte $F$ (1994). Predictive factors of long-term compliance with nasal continuous positive airway pressure treatment in sleep apnea syndrome. Chest, 105: 429-433.

11. Pieters T, Collard P, Aubert G, Dury M, Delguste P \& Rodenstein DO (1996). Acceptance and long-term compliance with nCPAP in pa- tients with obstructive sleep apnoea syndrome. European Respiratory J ournal, 9: 939-944.

12. Lindberg E, Taube A, J anson C, Gisland T, Svärdsudd K \& Boman G (1998). A 10-year follow-up of snoring in men. Chest, 114: 10481055.

13. Bloom J W, Kaltenbom WT \& Quan SF (1988). Risk factors in a general population for snoring. Importance of cigarette smoking and obesity. Chest, 93: 678-683.

14. J ennum P \& Sjøl A (1993). Snoring, sleep apnoea and cardiovascular risk factors; the MONCA II study. International J oumal of Epidemiology, 22: 439-444.

15. Koskenvuo M, Partinen M, Kaprio J , Vuorinen $\mathrm{H}$, Telakivi T, Kajaste S, Salmi T \& Heikkila K (1994). Snoring and cardiovascular risk factors. Annals of Medicine, 26: 371-376.

16. Kripke DF, Ancoli-lsrael S, Klauber MR, Wingard DL, Mason WJ \& Mullaney DJ (1997). Prevalence of sleep-disordered breathing in ages 40-64 years: a population-based survey. Sleep, 20: 65-76.

17. Ng TP, Seow A \& Tan WC (1988). Prevalence of snoring and sleep breathing-related disorders in Chinese, Malay and Indian adults in Singapore. European Respiratory J oumal, 12: 198-203.

18. Redline S, Tischler PV, Hans MG, Tosteson TD, Strohl KP \& Spry K (1997). Racial differences in sleep-disordered breathing in AfricanAmericans and Caucasians. American J oumal of Respiratory and Critical Care Medicine, 155: 186-192.

19. Rechstaffen A \& Kales A (1968). A Manual of Standardized Terminology, Techniques and Scoring System for Sleep Stages of Human Subjects. Govemment Printing Office, Washington, DC, USA.

20. Atlas Task Force of the American Sleep Disorder Association ASDA Report (1991). EEG Arousals: scoring rules and examples. Sleep, 15: 173-184.

21. The report of an American Academy of Sleep Medicine Task Force (1999). Sleep-related breathing disorders in adults: recommendations for syndrome definition and measurement techniques in clinical research. Sleep, 22: 667-689.

22. Bixler EO, Vgontzas AN, Ten Have T, Tyson K \& Kales A (1998). 
Effects of age on sleep apnea in men: I. Prevalence and severity. American J ournal of Respiratory and Critical Care Medicine, 157: 144-148.

23. Young $T$ (1992). Age dependence of sleep disordered breathing. In: Kuna ST, Surrat PM \& Remmers JE (Editors), Sleep and Respiration in Aging Adults. Elsevier, New York.

24. He J , Kryger MH, Zorick FJ , Conway W \& Roth T (1988). Mortality and apnea index in obstructive sleep apnea. Chest, 94: 9-14.

25. Lavie P, Herer P, Peled R, Berger I, Yoffe N, Zomer J \& Rubin AH (1995). Mortality in sleep apnea patients: a multivariate analysis of risk factors. Sleep, 18: 149-157.

26. Lindberg E, J anson C, Svärdsudd K, Gislason T, Hetta J \& Boman G (1998). Increased mortality among sleepy snorers: a prospective population based study. Thorax, 53: 631-637.

27. Young T, Hutton R, Finn L, Badr S \& Palta M (1996). The gender bias in sleep apnea diagnosis. Are women missed because they have different symptoms? Archives of Internal Medicine, 156: 24452451.
28. Gislason T, Benediktsdóttir B, Björnsson G, Kjeld M \& Kristbjamarson H (1993). Snoring, hypertension and the sleep apnea syndrome. An epidemiologic survey of middle-aged women. Chest, 103: 1147-1151.

29. Kribbs NB, Pack Al, Kline LR, Smith PL, Schwartz AR, Schubert NM, Redline S, Henry J N, Getsy JE \& Dinges DF (1993). Objective measurement of patterns of nasal CPAP use by patients with obstructive sleep apnea. American Review of Respiratory Disease, 147: 887-895.

30. Engleman HM, Martin SE \& Douglas NJ (1995). Compliance with CPAP therapy in patients with the sleep apnoea/hypopnoea syndrome. Thorax, 49: 263-266.

31. Pépin J L, Leger P, Veale D, Langevin B, Robert D \& Lévy P (1995). Side effects of nasal continuous positive airway pressure in sleep apnea syndrome. Chest, 107: 375-381.

32. Baker J, Rose V \& Ware C (1987). Obstructive sleep apnea: therapeutic compliance. Transactions of the American Clinical and Climatological Association, 99: 224-229. 